\title{
Bioethical Principals in the Conduct of Doctors
}

OPINION

\author{
Dilza Teresinha Ambrós Ribeiro1, José Hiran Gallo², \\ Guilhermina Rego ${ }^{3}$
}

\section{Abstract}

Objective: The present study aims gather further information towards the practice of medicine, particularly regarding bioethical principles, which are essential for the full and correct medical practice all over the world.

Method: This study is a theoretical essay on the bioethical principles related to the professional activity of medical doctors. Therefore, it was carried out a non-systematic review of the literature, which allows a critical analysis of this issue.

Results: Through considering the theoretical guidelines there is a close relationship between the principle of respect for persons and human dignity itself. Also the results of this study suggest that respect for persons, namely personal autonomy, is steadily protected by means of constitutional and infra-constitutional norms.

Conclusion: For these principles to be effective it is indispensable to have common efforts between the political power and overall society, so that public policies may be implemented to favor patients in the healthcare setting. Also the continuous training of physicians is needed for an adequate application of universal bioethical principles.

\section{Introduction}

The present study carries out a non-systematic review, discussing the beginnings of bioethics, its principles, its premises and its objectives, performing a theoretical essay of this issue, related to the professional activity of doctors. This historical and theoretical framework aids in improvement of human action, especially in the field of medicine.
1 Faculty of Medicine of the University of Porto, Portugal; Federal University of Acre, Rio Branco, Acre, Brazil.

2 Federal Council of Medicine, Brasilia DF, Brazil.

3 Faculty of Medicine of the University of Porto, Portugal.

\section{Contact information:}

\section{Dilza Teresinha Ambrós Ribeiro.}

Address: Faculty of Medicine of the University of Porto, Portugal. Alameda Prof. Hernâni Monteiro, 4200-319, Porto, Portugal.

झ dilzaambros@hotmail.com
Keywords
Bioethics; Professional Practice; Principles of Biomedical Ethics; Medical Complaints. 
Thus, it is expected that this study will promote a positive insight regarding a decrease in the rate of medical error.

In the year 1927, the German writer Paul Max Fritz Jahr [1] was the first to use the term bioethics. At that time, he characterized bioethics as the recognition of ethical obligations not only towards humans, but also towards all living creatures. Jahr's work was published 47 years ahead of the more general appearance of the term and he proposed a "bioethical imperative: respect towards all living beings".

This term was previously attributed to Van Rensselaer Potter [2], who in 1970 characterized bioethics as the science of survival. Potter initially used the term to establish an interface between science and humanities, with the aim of ensuring greater quality of life in the future. Also in 1970, André Hellegers used the term to define new studies that were being proposed in the field of human reproduction, at the time when the Kennedy Institute of Ethics was created.

At the end of the 1980s, Van Potter [3] emphasized the interdisciplinary and wide-ranging characteristics of bioethics, defining it as having global scope, i.e. global bioethics. This author's objective was to reestablish the original focus of bioethics, including but not becoming restricted to discussions of medical and health issues, thereby broadening the subject towards new environmental challenges. Thus, his publication "Bioethics: A bridge to the future" became his most well-known legacy.

Although, as stated by Sgressia [4], Van Rensselaer Potter may have disseminated the term, the discipline of bioethics emerged in the United States through the work of the philosopher Daniel Callahan and the psychiatrist Willard Gaylin.

Scholars are unable to discern any clear separation between the important fields of scientific knowledge and humanistic knowledge. From their point of view, differentiation between ethical values, which are part of humanistic culture, are inherent to hu- man life. Thus, indiscriminate scientific-technological processes pose a threat to humanity and life on Earth. Following this line of thought, the scope of ethics needs to be broadened, to encompass the biosphere, all human interventions and life in general.

Human actions should be taken with due regard for bioethics. In the field of medicine, this is necessary because bioethics in clinical practice is dynamic and is based on the best interests of the affected person and also of humanity, simultaneously. If the tools of this field are not used as instruments to transform doctor/patient relationships, the moral evaluation of clinical practice would be reduced to the minimum requirements, which are insufficient for practice and application of deontological norms and institutional regulations.

The definition of bioethics that is used in this paper is the one given by the Encyclopedia of Bioethics, published in 1976, as quoted by Sgressia [4]:

The systematic study of human conduct in the field of life sciences and healthcare, when such conduct is examined in the light of values and moral principles.

The field of life sciences and healthcare includes the biosphere beyond medicine, as well as interventions relating to medical professions and also the populations involved in demographic and environmental issues, thereby protecting moral values and definitions of criteria, judgements and limits of what is lawful and what is unlawful.

Consequently, universities have included bioethics classes in their curricula as a basic subject within healthcare professional's training. In Europe, many scientific meetings have been held to discuss this issue and to include bioethics in doctors' training of doctors. Chairs have been established and have gained space in various places, including Brazil.

Academic training in Brazil also needs to open up space for discussions regarding the absence of 
bioethics in medicine. All professionals, whether they are in the field of medicine or in other fields, are susceptible to making mistakes due to the work environment, excessive workload or deficiencies of auxiliary diagnostic devices, among other numerous factors.

Bioethics as a curriculum subject is considered to be an effective vehicle for ensuring good doctor/patient, doctor/diagnosis and doctor/human conduct relationships. The greatest contribution of bioethics is believed to consist of showing that the solutions to everyday ethical dilemmas are clad in transitory truths and must always maintain unconditional respect for the dignity and fundamental rights of people with illnesses. Nonetheless, to understand the bioethical principles, it is necessary observe its origins.

\section{Origins of bioethics}

Following Van Rensselaer Potter bioethics began in the United States with the philosopher Daniel CaIlahan and the psychiatrist Willard Gaylin [4], and later gained strength in Europe, the United States, Canada and Australia. This field of study embraces rational analysis of moral problems regarding biomedicine and their connections with the fields of law and human sciences. Moreover, bioethics relates to creation of ethical boundaries based on people's values and rights, while respecting religious beliefs, with a rational methodological foundation that is scientifically sound, which should guide professional conduct.

In view of the transformations that medicine has faced over recent years, the importance of medical ethics and bioethics for comprehending the realities and anticipating new issues imposed on the lives of those who deal with healthcare has grown. Bioethics is a new word, as previously mentioned, that first appeared as such in 1970 and which crystalizes movements, aspirations, discourse and practices that either question or enable advances in biomedical techniques. Much discussion regar- ding its statute, methods and objectives has also been raised.

Medical ethics is a special form of ethics that relates to moral issues faced by the medical profession. Thus, it may be presented in a form that is reduced to coded deontology. This dimension would be applied to the field of healthcare, while its doctrinal contraposition (i.e. bioethics) occupies a broader space as an autonomous philosophy that is pertinent to all manifestations of ethical cogitations, whether professional or not, that occur within the life sciences. Numerous intermediate opinions can be placed in the ontological space delimited between these two extremes (ethics and bioethics) but they are all for the purpose of the greatest gift, which is life.

In view of these new paradigms, many scholars have observed discrepancies between the technical-scientific development that the medical community faces, and the reality of consultation offices and hospitals, particularly regarding the quality of healthcare and humanization.

Complaints regarding professional errors are frequent in Brazil. However, the most recurrent complaint relates to dehumanization of medical practice and neglect of patients. Thus, the separation between the ethical guidelines recommended by codes and what is practiced by healthcare professionals is becoming increasingly sharp. This context is the backdrop for the increasing number of ethical-professional cases against doctors, which gain enormous visibility through the media.

All this adds towards discrediting the figure of the doctor, and to insecurity and repugnance among large numbers of patients. This status quo indicates that there is an increasingly urgent need for incisive changes in the training of medical students. The profession needs to be humanized and professionals need to be more sensitive to patients' needs and to values relating to life. There is an urgent need to reverse this situation so as to make care affective, humane and kind. 
Professional training influences doctors' conduct and the relationship that they establish with patients. Thus, teaching of medical ethics and bioethics in universities in Brazil and elsewhere in the world is justifiable, with the aim of improving doctors' conduct and thus enabling provision of quality healthcare to the population, by professionals who are, above all, ethical and humanized.

The word "bioethics" was well disseminated and defended by Van Rensselaer Potter in his publications: 1) Bioethics: The Science of Survival [3]; and 2) Bioethics: Bridge to the Future [2]. In both of these, this scholar sought to demonstrate that ethical values cannot be separated from biological facts. Nonetheless, with the advance of medicine, especially biomedical technology, new challenges to humans have been posed. Thus, Potter defended the need for a true ethics of life, of all commonwealth of life. This topic is not only present in universities but also should go systematically with scientific accomplishments regarding human life.

Regarding this new concept, Potter explained [2]:

Mankind is urgently in need of new wisdom that will provide the "knowledge of how to use knowledge' for man's survival and for improvement in the quality of life. (...) I therefore propose the term 'bioethics' in order to emphasize the two most important ingredients in achieving the new wisdom that is so desperately needed: biological knowledge and human values.

With his view on quality of life and human survival, Potter realized that there was a need for a new model of science that would have the capacity to integrate biology, humanity sciences and social sciences. This approach would need above all to take nature of mankind into consideration, along with the relationship between man and the biological and physical world. This new science would allow reflections regarding scientific and technological advances and their limits. For this author, the most important aspect was that the future of mankind would be ensured through consequent improvements of quality of life in future generations. Thus, a survival instinct alone would not be not enough.

Also according to Potter, a science of survival should urgently be developed, starting from a new kind of ethics, i.e. bioethics. This field should be based on biological concepts and on knowledge of human nature. This would allow delineation of the scope of biological knowledge so that it would then be possible to create public policies that were aimed towards mankind's survival and improvement of quality of life.

In the United States, bioethics emerged in association with occurrences that caused public outrage. In the year 1963, research was conducted on elderly individuals, in which they received tumor cells without giving prior consent. Another study involved 400 black people with syphilis between the 1940s and 1970s, with the objective of investigating the natural development of the disease in the human body. However, these people were left without treatment, even though penicillin had already been discovered. And of course the growing awareness of the war crimes committed by researchers in the Nazism was also instrumental with regard the emergence of a new biomedical ethics.

These occurrences caused public outrage. Consequently, in 1974, the National Commission for the Protection of Human Subjects of Biomedical and Behavioral Research was created in the United States, so that research would be guided by ethical principles that respected human life. After the creation of this commission, the Belmont Report was established in 1978 [5]. This was a milestone in the emergence of the principlist approach to bioethics, as defended by Beauchamp and Childress [6]. The document elaborated by the commission presented three ethical principles that ought to guide research involving human beings. 
These principles were: respect for individuals, beneficence and justice. These authors indicated that these principles were the main characteristics of their theory, which is currently the predominant perspective in biomedical ethics.

\section{Principlism, bioethics and bio-scientific advances of globalized society}

In the year 1979, the researchers Tom Beauchamp and James Childress [6] developed a theory on applied ethics that was directed specifically towards biomedical ethics. After the Belmont Report, the authors of Principles of Biomedical Ethics redefined the three principles originally presented in the publication and also added the principle of nonmaleficence as an unfolding of the principle of beneficence.

Thus, principlism embraces four basic principles as norms of action towards biomedical practice, namely: a) respect for autonomy; b) non-maleficence; c) beneficence; and d) justice. Although principlism was based on a biomedical ethical theory, its acceptance has become so broad that it is used as a reference for bioethics in general. Whether this can be done from the basis that supports this theory is a question that will be addressed below.

Another interesting view to be added to these studies is that of the British philosopher William David Ross, expressed in 1930. He declared that the concept of a moral life was based on some basic, evident and indisputable principles that all humans consider mandatory at first glance, which were named prima facie duties. These are obligations that must be fulfilled, unless they conflict with another equal or stronger obligation in a given situation. Beauchamp and Childress [6] likewise advocated that among these prima facie duties are beneficence, non-maleficence and justice.

In the 1960s, the philosopher William Frankena constructed a theory that was in harmony with the ideas of Ross. This author affirmed that there are two basic principles or prima facie duties: beneficence and justice (or equity).

Nevertheless, in the light of these authors' contributions, principlism has generated criticism ever since it emerged. On the one hand, there is the issue of the relative nature of the principles, which leads to conflicts between them, because in practice it is not always possible to follow them equally. On the other hand, it is impossible not to recognize the operational advantage of principlism, which is a necessary, albeit not always sufficient part of the decision-making process. Principles make it easier to analyze concrete cases and put order into such analyses, which thereafter may necessitate other values in order to deepen the ethical analysis. In contemporary bioethics, the consensus is that principlism presents a set of basic rules that cannot be ignored even if they are not recognized as having unconditional characteristics of principles.

These authors also differentiate between the terms "principles" and "rules". Rules are to be understood as normative generalizations with a stricter reach than principles. They function as precise norms for actions that establish what should be done under certain circumstances. Principles, however, are general guidelines that allow formulation of rules and more detailed lines of action.

These principles, according to the theory of Beauchamp and Childress [6], are closer to prima facie, especially due to the influence of the publication "The Right and the Good", by W. D. Ross, already mentioned in this paper. Initially, the prima facie validity of principles causes them to be considered in an equal manner. However, subsequently, depending on the context, these may be abandoned due to other duties that are supposedly more important and which were shown to be necessary in the light of certain moral conflicts.

It is important to note that there is no hierarchy among these principles. They all have the same value at the outset and should be respected, but as 
other sufficiently strong reasons demand the use of one or other principle, an "infraction" may be justified. According to Beauchamp and Childress [6], some actions may be equally wrong or right, prima facie, depending on circumstance, because "two or more norms conflict under the circumstances".

When there is a conflict, the moral agent needs to compare the different weights of each possible action. Given the principles that are prima facie and that conflict with each other in a given context, all elements involved in the situation should be urgently considered. According to one principle or another, the course of action will be determined by examining what is right or wrong within the individual's circumstances.

Knowing how to choose the best medical conduct is based on practice, according to the orientation of the Federal Medical Council of Brazil [7] in its publication Introduction to Bioethics:

It does not mean that this is the application of theory, but rather, other knowledge that deals with a specific object: action.

This differentiation between theory and practice demonstrates that wisdom is not acquired in the same way that theoretical knowledge is acquired. Hence, ethics can only be conceived from a theoretical and rationalist perspective. Predominance of a perspective based on a humanist principle brings either ambiguity or at least one question that needs to be answered: does technical rationality have a sufficiently long reach to cover all aspects of human life, particularly ethical aspects?

Mankind is divided along two lines according to Kant's philosophy, as stated in the aforementioned publication of the Federal Medical Council of Brazil [7]: ...the theoretical, which represents the ideal of absolute certainty within the limits of scientific knowledge, and the moral, which to be comprehended in the sphere of its liberty must extend its liberty to a transcendental height in which it is located far from the plane of experience.

The concept of good in ethics states that each person is what he/she becomes through each moment of existence. An ethical code that uses only one criterion can be mistaken for an irreducible data point from the reality. To accept this is lucidity and authenticity, to deny it is malice. Biomedical ethics have given emphasis to the interpersonal relationship between healthcare professionals and their patients, in which beneficence, non-maleficence and autonomy have had a prominent role, somewhat overshadowing the theme of social justice.

If someone were to search for the term "bioethics" in a dictionary or encyclopedia, they would probably not find it. This neologism is a new concept that was invented and disseminated by the American oncologist and biologist Van Rensselaer Potter [5] in his book "Bioethics: a bridge to the future", in 1971. The meaning of the term has evolved from how Potter first intended. Potter used the term to refer to the importance of the biological sciences for improving quality of life. In other words, for him, bioethics would be the science that would guarantee survival for our planet.

At first, the term bioethics was thought of as specific case of applied ethics. This category of ethics is also known as practical ethics and has the aim of managing the conflicts and moral controversies that are present within the scope of life and health sciences from the viewpoint of a value system known as "ethics". Bioethics is different from mere theoretical ethics, which is concerned with the form and "cogency" of ethical concepts and arguments. Although bioethics cannot withdraw from formal 
questions (which are traditionally studied through meta-ethics), it has been urged that this field should be used to resolve concrete ethical conflicts that emerge from social interactions, such as longstanding issues.

Bioethics requires a moral anthropological reference paradigm that implicitly highlights the supreme value of the person, and his/her life, liberty and autonomy. However, this principle may sometimes conflict with another, regarding the quality of life that this individual deserves. These principles do not always fit in the same case.

Thus, bioethics needs to find the means to solve conflicts of interest and values without resorting to transcendent principles of authority (or those that are external to the dynamics of the social imaginary), but only to those that are "immanent" through negotiation among moral agents that should in principle be considered cognitively and ethically competent. It can be said that the function of bioethics is threefold and is recognized academically and socially: 1) descriptive - consisting of describing and analyzing the conflicts that appear within the scope of health and life sciences; 2) normative - descriptively prescribing the behaviors that can be considered reprehensible and those that are considered correct; 3) protective - aiding those involved in disputes of interests and values, as much as possible, while when necessary prioritizing the "weakest", as established by Schramm [8].

Regarding comprehension, bioethics as a special form of ethics is first and foremost a field of philosophy. Thus, it can be defined in several ways: according to traditions, authors, contexts and maybe even the subjects under examination. Potter presented the following definitions [5]:

I therefore propose the term Bioethics in order to emphasize the two most important ingredients in achieving the new wisdom that is so desperately needed: biological knowledge and human values.
The definition of Reich [9] is:

Bioethics is the systematic study of the moral dimensions -including moral vision, decisions, conduct and policies - of the life sciences and health care, employing a variety of ethical methodologies in an interdisciplinary setting

On the other hand, Kottow [10] stated that bioethics

Is a very specific rational practice that sets in motion, simultaneously, a knowledge, an experience and a normative competence, in a particular context of action defined by the prefix 'bio'.

\section{According to Hottois [11]:}

The word bioethics defines a set of research, speeches and practices, which as a norm are pluridisciplinary and have the objective of enlightening and solving ethical issues evoked by the advances and application of biomedical techno-sciences.

Renowned scholars have advocated that bioethics should not be used as a tool for indiscriminate use to justify the finitude of natural resources - which belong to all - and the corporality, pleasure and pain that inflict all. Bioethics should be considered as a historical intervention among populations that have been socially excluded from the process of social development. Therefore, bioethics takes on a humanist and social viewpoint that dignifies existence and considers human life to be the central position of the world. It is important to note that bioethics is part of life and is always being updated, such that it becomes contemporary, imposes new views and takes new forms in the light of current challenges. Thus, it is able to adapt to cultures at the core of the life of populations and in the practices of professions and occupations. 
The importance of bioethics is growing steadily as the current level of sciences regarding biotechnological, biomedical and scientific investigations allow humans to carry out interventions in our their own bodies. This can be observed in cases of genetic manipulation and other forms of research involving humans. This is why there is a need for ethical evaluations in these interventions. Human dignity needs to be respected in full and not just as half value.

The most accurate studies on this topic have sought to provide overall comprehension of the philosophical aspects of bioethics in the light of technological/scientific advances in the realm of research focusing on humans. Moreover, the current situation of legislation on this subject also needs to be considered, given that the law has not been able to keep pace with the rhythm of change and novelties brought by scientific and cultural globalization.

The literature on this subject shows that bioethics began to take shape in ancient times when the first ethical problems due to medical practice appeared. This is easily seen through analyzing the famous Oath of Hippocrates, which ensures that medicine is used for the benefit of patients, following knowledge and reason, and never to impair or do harm to anyone.

Based on these studies, ethics can be defined as a science that molded that what is known today as bioethics. In the classical definition proposed by Aristoteles, ethics is a type of moral science that consists of philosophical reflection on the actions of mankind and their purposes. The term comes from the Greek word ethos, which means way of being, property of character or even fixed housing. In the other hand, the word moral originated from Latin - morus - meaning uses and customs.

Martin Heidegger, a German philosopher of the $20^{\text {th }}$ century, affirmed that good does not mean morally organized, but that which is or should be produced or can produce that which is needed. Thus, although bioethics encompasses medical ethics and morals, it is not limited to them. Bioethics also includes other fields and disciplines that involve various forms of scientific knowledge that are connected in a particularly way with philosophy and human actions, such as medicine, biology, law and sociology, among others.

It can therefore be inferred that, regardless of the field of knowledge, ethics should mediate the mismatch between theoretical and practical knowledge, in seeking the correct attitude. On the other hand, bioethics is an interdisciplinary field of contemporary applied ethics that has been consolidating since the 1970s as one of the main configurations of lay morality.

From a sociocultural perspective, bioethics emerged from the critical moral sensibility of social movements in the United States in the 1960s, when absolute norms and values that were inherited from tradition were questioned in the name of primordial principles [12]. Even though the lesson of Gadamer [13] regarding humanist ethics did not refer specifically to bioethics, its importance can be seen in the statement that:

The set of human ethics is essentially different from nature due to the fact that in nature there are not only capacities and forces in place, but because mankind comes to be as it is by what it does and how it behaves.

Thus, following a humanist rationale, individuals who are responsible for conducting research involving human beings are not the only ones who need guidance regarding bioethics. The subjects of the experiments, i.e. the patients, those who are subjected to the position of volunteers or guinea pigs for new discoveries, should also receive guidance [14].

The scholar Corbin [15] highlighted that it was important that volunteers within biomedical research should give their free and informed consent: 
Free and informed consent should always be obtained when possible, when it does not represent an inconvenience for the patient. In this case, a doctor who did not ask for consent would be committing a serious mistake.

The philosophical comprehension of bioethics goes beyond joining biology to ethics. For bioethics to be applied from a philosophical viewpoint, it is inevitable that it will be regarded from an interdisciplinary angle, such that memory, forgiveness, promise and questioning are added to its time (postmodernity/globalization). Thus, it is expected that doctors, researchers, lawyers, jurists, legislators, philosophers, religious people and all others that act in the scientific world should unite to establish a set of norms that can guide conduct that is more humane and dignified [16].

\section{Conclusion}

Some professions are subjected to a more rigorous code of conduct through their very nature. Medicine is one of them. Interestingly, the themes raised by bioethics are, in practice, the same as those raised by doctors and their entities in relation to society, in seeking to define normative guidelines for these professionals.

Bioethics can establish a bridge with medical ethics, thus opening a space for reflection and stimulating construction of knowledge that is not necessarily normative. That is the reason why doctors' practical activities are disciplined through the Code of Medical Ethics, while research activities follow the resolutions on research involving human beings. Meanwhile, bioethics is the field for reflection on the values involved in the life sciences [17].

Through considering the theoretical guidelines, a close relationship was observed between the principle of human dignity and human dignity itself, as well as the advance achieved through its protection by means of constitutional and infra-constitutional norms. However, for these rules to be effective, it is indispensable to have common effort between the power of the State and society, so that public policies may be implemented to favor patients. In addition, awareness must be raised regarding the special needs of this portion of society. Regarding the discipline of bioethics in professionals' training, it has to be borne in mind that although bioethics is a new subject within medical practice it is unavoidable that new generations of doctors are deeply acquainted with its main principles.

\section{Disclosure}

The authors report no conflicts of interest.

\section{References}

1. Jahr F. Bioética: a panorama of the human being's ethical relations with animals and plants. Stuttgart Nr: Kosmos; 1927.

2. Potter VR. Bridge to the future. New Jersey: Prentice-Hall/ Englewood Cliffs; 1970.

3. Potter VR. Bioethics: the science of survival. Perspectives in Biology and Medicine. 1980; 14:127-53.

4. Sgressia E. Manual de Bioética. Edições Loyola; 1996.

5. National Commission for the Protection of Human Subjects of Biomedical and Behavioural Research. The Belmont Report. Ethical Principles and Guidelines for the Protection of Human Subjects of Research. Washington D.C. Government Printing Office, 1978. p. 48-55.

6. Beauchamp T, Childress J: Principles of Biomedical Ethics. Oxford University Press, New York, 2013, $7^{\text {th }}$ edition.

7. Conselho Federal de Medicina Resolução 1.488/98 Brasília, CFM, 1998. Modificada pela Resolução n 1940/2010 de 09 de Fevereiro de 2010 [Internet]. [Acesso em 11 Dez 2016]. Disponível em: http://www.portalmedico.org.br/resolucoes/ cfm/1998/1488 1998.htm

8. Schramm FR. 2002. Bioética para quê? Rev camil saúde. 2002; 1(2): $14-21$

9. Reich WT (editor): Encyclopedia of Bioethics, Simon \& Schuster and Prentice Hall International, London, 1999.

10. Kottow MH. Introducción a la bioética. Chile: Editorial Universitaria; 1995. p. 53. 
11. Hottois G. Bioética y medio ambiente. Revista Colombiana de Bioética. 2001; 3: 145-153.

12. Engelhardt $\mathrm{H}$ : The Foundations of bioethics. Oxford University Press, New York, 1986.

13. Gadamer HG. Verdade e método: traços fundamentais de uma hermenêutica filosófica. 3ª. ed. Petrópolis: Vozes; 1999.

14. Singer P. Practical Ethics. Cambridge University Press, Cambridge, 1993, 2nd edition.

15. Corbin, M. Du libre arbitre selon S. Thomas d'Aquin. Arch philos. 1991; 54(2): 177-212.

16. Dworkin RB. Limits: The role of the law in bioethical decision making. Indiana University Press, Indiana, 1996.

17. Veatch R: The Patient-Physician Relation. The Patient as a Partner 2, Indiana University Press, Bloomington and Indianapolis, 1991.

Publish in International Archives of Medicine

International Archives of Medicine is an open access journal publishing articles encompassing all aspects of medical science and clinical practice. IAM is considered a megajournal with independent sections on all areas of medicine. IAM is a really international journal with authors and board members from all around the world. The journal is widely indexed and classified Q2 in category Medicine. 